\title{
Aeromonas hydrophila: Antimicrobial Susceptibility and Histopathology of Isolates from Diseased Catfish, Clarias gariepinus (Burchell)
}

\author{
Laith $\mathrm{AR}^{*}$, and Najiah M
}

Department of Aquaculture, Faculty of Fisheries and Aqua-Industry, Universiti Malaysia Terengganu, 21030 Kuala Terengganu, Malaysia

\begin{abstract}
Antimicrobial resistance in bacterial pathogens is a global public health problem. The aim of this research was to reveal the distribution and antimicrobial drug resistance of bacterial pathogens in diseased catfish, Clarias gariepinus (Burchell) from Marang River Terengganu, Malaysia. Eleven isolates of Aeromonas hydrophila were derived from diseased fish. Commercial biochemical identification kit (BBL-Crystal) and the PCR products of 16S rDNA was used to identify the isolated bacterial strains. Disc diffusion method using 6 types of antibiotic discs was performed for antibiotics susceptibility testing. The majority of isolated bacteria were $A$. hydrophila. All isolates of $A$. hydrophila were resistance to Ampicillin and susceptible to tetracycline of the analyzed isolates against the tested antibiotics. Multiple drug resistance index (MAR) for all isolates was ranged from 0.10 to 0.50 . Isolates of $A$. hydrophila showed $\beta$ - haemolytic pattern on blood agar. Clinically; exophthalmia and dermal lesions with hyperaemia and cellulites of the fins were observed. Necropsy revealed yellow foci on the liver surface, tightly full gall bladder with emerald green bile and swollen, friable kidney and spleen. Histopathologically indecated skin necrosis, hyperplasia in the secondary lamellae of gill, degenerative changes in glomerular epithelium in kidney, vacuolar degeneration in hepatocytes, hyperplasia in the lymph follicles of spleen, edema, and focal hyaline degeneration in muscles. Therefore, routine monitoring of drug susceptibility pattern over time is necessary.
\end{abstract}

Keywords: Antibiogram; Hemolytic analysis; Aeromonas hydrophila; Histopathological; Catfish; Clarias gariepinus (Burchell)

\section{Introduction}

High antibiotic resistance is seen in bacterial infections caused by members of the genus Aeromonas [1]. They are amid the most common diseases of fish especially those in pond systems containing recirculation [2]. The emergence of resistance to antimicrobial agents in bacterial pathogens is a global public health problem [3]. A. hydrophila is a microorganism widely distributed in nature: in water, soil, food. It is also part of the normal bacterial flora of many animals. As an opportunistic microorganism it is a secondary biological agent that contributes to the occurrence of a fish disease and its deterioration Yu et al [4]. A. hydrophila is a Gram-negative aerobic and facultative anaerobic, oxidase-positive motile bacterium that dwells in aquatic environments and in gastrointestinal tracts of healthy fish [5].

Significant mortalities due to $A$. hydrophila infection were recorded in the South and South-East Asia farmed fish [6]. In the study of Musa et al stated that bacterial isolates from sick freshwater ornamental fish from aquarium shops in Terengganu-Malaysia consisted of mostly A. hydrophila (60\%) [7]. The bacterium causes diverse pathologic conditions such as dermal ulceration, rotting of the tails, fin haemorrhagic, septiceamia, red sores, exophthalmia, erythrodermatitis and scale protrusion especially for common carp Cyprinus carpio $[8,9]$

Chronic infections could lead to ulceration, inflammation, and dermal lesions with focal haemorrhages Cipriano [8] and during acute septicaemia, the liver and kidney are the common target organs [10]. According to Wooley [11] antibiotic resistance is a major problem when dealing with $A$. hydrophila infections. Therefore, the main objectives of the present study areto isolate and identify of A. hydrophila from farmed diseased catfish, Clarias gariepinus (Burchell) and to evaluate their antibiotic susceptibility profile along with the clinical and histopathological effects in diseased fish.

\section{Materials and Methods}

\section{Sample fish}

About 60 diseased catfish, Clarias gariepinus were collected from a local farm culture Marang River Terengganu, Malaysia $\left(05^{\circ} 12^{\prime} \mathrm{N}, 103^{\circ} 13^{\prime} \mathrm{E}\right)$. The fish weighed from 350 to $800 \mathrm{~g}$. The fish were anaesthetised with Tricaine methanesulfonate (MS-222) and then dissected according to Wilson [12] and performed by standard methods [13].

\section{Bacterial isolation}

Lesions from skin, fin and gill, were inoculated onto Trypticase Soy Agar (TSA) (Merk, Germany) and incubated aerobically at $28^{\circ} \mathrm{C}$ for $24 \mathrm{~h}$. Then internal samples were acquired alike aseptically from the kidney, liver, spleen and the infected muscles. The plates were examined for bacterial growth. Dominant colonies were selected, re-streaked on Trypticase Soy Agar (TSA). Cultures were placed in $20 \%$ glycerol and supplemented in Trypticase Soy Broth (TSB) for storage at $-80^{\circ} \mathrm{C}$. Dominant colonies were selected for bacterial isolation to establish the optimal number of bacterial cells, and undergoing thorough purification procedure until pure colonies were established to be sure that dominant colonies were not contaminated.

*Corresponding author: Laith Abdul Razzak, Department of Aquaculture Faculty of Fisheries and Aqua-Industry, Universiti Malaysia Terengganu, 21030 Kuala Terengganu, Malaysia, Tel: 609-6684391; E-mail: saiflaith3@yahoo.ca

Received November 30, 2013; Accepted December 24, 2013; Published December 31, 2013

Citation: Laith AR, Najiah M (2013) Aeromonas hydrophila: Antimicrobial Susceptibility and Histopathology of Isolates from Diseased Catfish, Clarias gariepinus (Burchell). J Aquac Res Development 5: 215 doi:10.4172/21559546.1000215

Copyright: $\odot 2013$ Laith AR, et al. This is an open-access article distributed unde the terms of the Creative Commons Attribution License, which permits unrestricted use, distribution, and reproduction in any medium, provided the original author and source are credited. 


\section{Phenotypic characterization}

Phenotypic characterization of $A$. hydrophila were carried out biochemically to species level by using following tests: Gram staining, motility, catalase, Kovac's oxidase, indole typical growth reaction on Triple sugar iron agar, oxidation and fermentation, urease test, $\mathrm{H} 2 \mathrm{~S}$ production, Methyl Red-Voges Proskauer (MR-VP), reduction of nitrate to nitrite, haemolysin production, and arginine dihydrolase. Isolates of $A$. hydrophila were then identified by using a commercial Identification System kit (BBLTM Crystal E/NF, USA) [14].

\section{Identification of the isolates}

The purified isolates were amplified in BHI broth and DNA extraction was done with a DNA extraction kit. The bacteria were subjected to the PCR with universal $16 \mathrm{~S}$ rRNA primers and the PCR products were detected by agarose gel electrophoresis and sequenced. The sequences were performed by comparative analysis with the Genbank databases for identification of the isolates [15]

\section{Antibiogram}

Antibiogram testing was carried out using the disc diffusion method. Antibiogram was performed on Mueller-Hinton Agar (Oxiod, England). Standard guidelines were used for result evaluation [16]. Six antibiotic disk namely ampicillin $(10 \mu \mathrm{g})$, tetracycline $(30 \mu \mathrm{g})$, nitrofurantoin $(50 \mu \mathrm{g})$, colistin sulphate $(25 \mu \mathrm{g})$, florfenicol $(30 \mu \mathrm{g})$ and novobiocin $(10 \mu \mathrm{g})$ (Oxoid, England) were utilized. After a period of $24 \mathrm{~h}$ incubation, the zones of inhibition were compared and measured according to the manufacturer's instruction (NCCLS, 2006) (Table 1). In this study we chose only more commonly antibiotics that used to prevent and treated diseases in most farmed fish [16].

Based on the zone of inhibition, the characterizations of strains were investigated as sensitive, intermediate, or resistant. The formula below is used to calculate the Multiple Antibiotic Resistances (MAR index) of the present isolates against tested antibiotics.

MAR index $=\mathrm{X} /(\mathrm{Y} \times \mathrm{Z})$

Where;

X-Total of antibiotic resistance case

Y-Total of antibiotic used in the study

Z-Total of isolates [17].

When the use of antibiotics is seldom or of low dose use for animal of treatment, the MAR value is usually equal to or less than 0.2. In contrast, the elevated rate of use or the high risk of exposure of antibiotics for animal treatment will yield an MAR index value which is more than 0.2 .

\begin{tabular}{|l|l|l|l|}
\hline Antibiotic & $\begin{array}{l}\text { Sensitive } \\
(\mathbf{m m})\end{array}$ & $\begin{array}{l}\text { Intermediary } \\
(\mathbf{m m})\end{array}$ & $\begin{array}{l}\text { Resistant } \\
(\mathbf{m m})\end{array}$ \\
\hline Ampicillin & $\geq 17$ & $14-16$ & $\leq 13$ \\
\hline Colistin sulphate & $\geq 11$ & $9-10$ & $\leq 8$ \\
\hline Florfenicol & $\geq 18$ & $15-17$ & $\leq 14$ \\
\hline Nitrofurantoin & $\geq 16$ & $13-15$ & $\leq 12$ \\
\hline Novobiocin & $\geq 17$ & $15-16$ & $\leq 14$ \\
\hline Tetracycline & $\geq 19$ & $15-18$ & $\leq 15$ \\
\hline
\end{tabular}

(Source: Clinical and Laboratory Standard Institute, 2006)

Table 1: Breakpoints for 6 antibiotics according to the Clinical and Laboratory Standard Institute Standards.

\section{Haemolytic activity}

The test organisms were cultivated on blood agar (Oxoid, England). Plates were incubated at $28^{\circ} \mathrm{C}$ for 24 to $48 \mathrm{~h}$. The existence of clear zones around the colonies indicative of $\beta$-hemolysis (complete lysis of the red blood cell). Green zones around colonies signify $\alpha$-hemolysis. The green aura around a colony as an outcome of hemoglobin reduction to meta hemoglobin in red blood cells. No hemolysis is known as $\gamma$-hemolysis [18]

\section{Clinical Signs and Post-mortem}

\section{Examination}

The clinical signs were recorded and the fish were anesthetized in $100 \mathrm{mg} / \mathrm{L}$ tricaine methane sulfonate (MS-222). Fish were killed by transecting the spinal cord behind the skull for post-mortem examination and the gross lesions were recorded.

\section{Histopathological examination}

For histopathological studies, tissue specimens were obtained from skin, gills, liver, kidney, muscle and spleen. The tissue specimens were fixed in 10\% neutral buffered formalin. Dehydration and infiltration of tissue were carried on using automatic tissue processor (Leica ASP 300S, Germany). Samples were embedded in paraffin, and were sectioned using rotary microtome ( 4 to $5 \mu \mathrm{m}$ ) (Leica, Germany) and stained with Hematoxylin and Eosin (H\&E) according to the method described by [19].

\section{Data analysis}

Data was subjected to analysis of variance (ANOVA) and the mean was compared with last significant different (L.S.D) $\mathrm{P}<0.05$ using Gestate 12.1 program.

\section{Result}

\section{Clinical sings}

The diseased fish showed symptoms of increased respiration and lethargy, skin lesions such as white discoloration, shallow hemorrhagic ulcers or deep ulcers with exposed underlying muscle. Some fish showed marked hemorrhages on the base of the fins and vent. Others were dropsy, kidney congestion and enlargement, pale liver and gills, or gall-bladder enlargement with the accumulation of yellowish fluid in the body cavity.

\section{Bacterial Isolation and Identification}

Biochemical test delivered a preliminary identification of the $A$. hydrophila strain. Eleven isolates were identified as Gram negative (Figure 1), motile, oxidase-positive, catalase-positive (Table 2). The isolates induced $\beta$-hemolysis on blood agar. From the result of BBL Crystal Gram negative ID Kits the isolate was identified as A. hydrophila. The PCR products of $16 \mathrm{~S}$ rDNA were about $1500 \mathrm{bp}$ after agarose gel electrophoresis was done. It was demonstrated that the $16 \mathrm{~S}$ rDNA PCR products were $1523 \mathrm{bp}$ by sequencing. And the pair-wise alignments of the $16 \mathrm{~S}$ rDNA gene showed that the homology of the isolate to $A$. hydrophila was the most closest. Results of this study showed that $73.3 \%$ of bacterial strains isolated from diseased catfish, Clarias gariepinus (Burchell) were A. hydrophila and 6.6\% were Pseudomonas aeruginosa, Klebsiella pneumoniae, Flavobacterium indicum, Chryseobacterium indologenes and Chryseobacterium gleum.

\section{Antimicrobial resistance patterns}

Among 11 bacterial strains tested, all strains showed 100\% 


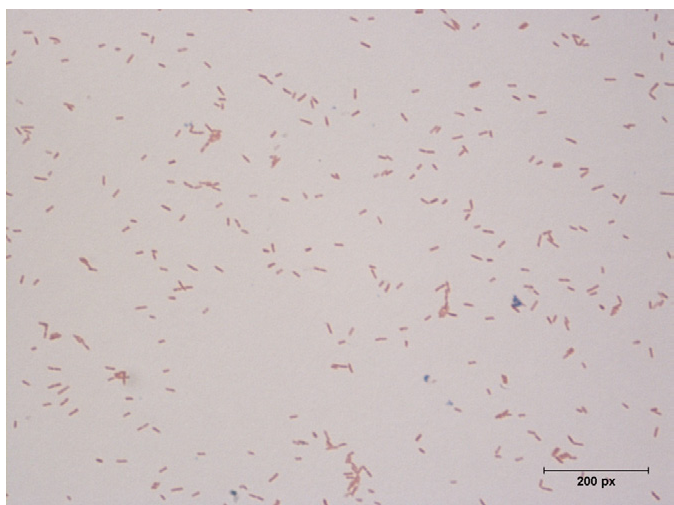

Figure 1: Typical morphology of Aeromonas hydrophila.

\begin{tabular}{|l|c|}
\hline Characteristic & Result of biochemical test \\
\hline Shape & + \\
\hline Motility & Negative \\
\hline Gram staining & + \\
\hline Indole & - \\
\hline MR & + \\
\hline VP & + \\
\hline Citrate utilization & + \\
\hline Catalase & - \\
\hline Triple Sugar Iron & - \\
\hline Urease & + \\
\hline Oxidase & \\
\hline Carbohydrate utilization & - \\
\hline Lactose & + \\
\hline Glucose & + \\
\hline Trehalose & + \\
\hline Starch Hydrolysis & + \\
\hline Gelatin Hydrolysis & + \\
\hline
\end{tabular}

Table 2: Biochemical characteristics of Aeromonas hydrophila.

\begin{tabular}{|l|c|c|c|c|c|c|c|}
\hline Isolate & $\begin{array}{c}\text { Nitrofu- } \\
\text { rantion } \\
\mathbf{( 5 0 )}\end{array}$ & $\begin{array}{c}\text { Colistin } \\
\text { sulphate } \\
\mathbf{( 2 5 )}\end{array}$ & $\begin{array}{c}\text { Ampicillin } \\
\mathbf{( 1 0 )}\end{array}$ & $\begin{array}{c}\text { Novobiocin } \\
\mathbf{( 3 0 )}\end{array}$ & $\begin{array}{c}\text { Tetracycline } \\
\mathbf{( 3 0 )}\end{array}$ & $\begin{array}{c}\text { Florfenciol } \\
\mathbf{( 3 0 )}\end{array}$ & MAR \\
\hline A1 & $\mathrm{S}$ & $\mathrm{R}$ & $\mathrm{R}$ & $\mathrm{S}$ & $\mathrm{S}$ & $\mathrm{S}$ & 0.3 \\
\hline $\mathrm{A} 2$ & $\mathrm{R}$ & $\mathrm{R}$ & $\mathrm{R}$ & $\mathrm{S}$ & $\mathrm{S}$ & $\mathrm{S}$ & 0.5 \\
\hline $\mathrm{A} 3$ & $\mathrm{~S}$ & $\mathrm{R}$ & $\mathrm{R}$ & $\mathrm{S}$ & $\mathrm{S}$ & $\mathrm{S}$ & 0.3 \\
\hline $\mathrm{A} 4$ & $\mathrm{~S}$ & $\mathrm{R}$ & $\mathrm{R}$ & $\mathrm{R}$ & $\mathrm{S}$ & $\mathrm{S}$ & 0.5 \\
\hline $\mathrm{A} 5$ & $\mathrm{~S}$ & $\mathrm{R}$ & $\mathrm{R}$ & $\mathrm{S}$ & $\mathrm{S}$ & $\mathrm{S}$ & 0.3 \\
\hline $\mathrm{A} 6$ & $\mathrm{~S}$ & $\mathrm{R}$ & $\mathrm{R}$ & $\mathrm{S}$ & $\mathrm{S}$ & $\mathrm{S}$ & 0.3 \\
\hline $\mathrm{A} 7$ & $\mathrm{~S}$ & $\mathrm{~S}$ & $\mathrm{R}$ & $\mathrm{S}$ & $\mathrm{S}$ & $\mathrm{S}$ & 0.1 \\
\hline A8 & $\mathrm{S}$ & $\mathrm{R}$ & $\mathrm{R}$ & $\mathrm{S}$ & $\mathrm{S}$ & $\mathrm{R}$ & 0.5 \\
\hline A9 & $\mathrm{S}$ & $\mathrm{R}$ & $\mathrm{R}$ & $\mathrm{S}$ & $\mathrm{S}$ & $\mathrm{S}$ & 0.3 \\
\hline A10 & $\mathrm{R}$ & $\mathrm{R}$ & $\mathrm{R}$ & $\mathrm{S}$ & $\mathrm{S}$ & $\mathrm{S}$ & 0.5 \\
\hline A11 & $\mathrm{R}$ & $\mathrm{R}$ & $\mathrm{R}$ & $\mathrm{S}$ & $\mathrm{S}$ & $\mathrm{S}$ & 0.5 \\
\hline$\%$ & $\mathbf{2 7 . 2 7 \%}$ & $\mathbf{9 0 . 9 0 \%}$ & $\mathbf{1 0 0} \%$ & $\mathbf{9 . 0 9 \%}$ & $\mathbf{0} \%$ & $\mathbf{9 . 0 9} \%$ & \\
\hline Resistance & & & & & & & \\
\hline
\end{tabular}

Table 3: Percentage (\%) of antibiotic Resistance (R) and Sensitive (S) of the present isolate and MAR Index for Aeromonas hydrophila.

resistance to ampicillin, $90.90 \%$ to colistin sulphat, and $27.27 \%$ to nitro furantoin. On the other hand, all isolates were $100 \%$ susceptible to tetracycline, and $90.90 \%$ to novobiocin and florfenicol as shown in Table 3.

\section{Antimicrobial Multi-resistance and MAR Index}

All 11 isolates showed multiple resistant patterns to at least one antibiotic. 7 strains were commonly resistant to 2 antibiotics with $63.6 \%$ multi-resistance patterns, while 3 strains were multiple resistances against 3 antibiotics with $27.2 \%$ of total strains, and 1 strain showed multiple resistances against 1 antibiotic with $9 \%$ of total strains. MAR index ranged from 0.1 to 0.5 (Figure 2) (Table 3).

\section{Antibiogram}

All isolated A. hydrophila strains showed 100\% resistant towards ampicillin and $90.90 \%$ to colistin sulphate. $9.09 \%$ of the isolates showed resistance for both novobiocin and florfenciol whereas $27.27 \%$ was observed for nitrofurantion. Isolates were $100 \%$ susceptible to tetracycline. There were significant differences $(\mathrm{P}<0.05)$ among all antibiotics used in present study in their effect of inhibition the growth of $A$. hydrophila as shown in (Figure 3). Tetracycline was the highest mean inhibition zone diameter $(25 \mathrm{~mm})$ against $A$. hydrophila while, ampicillin was the lowest mean inhibition zone diameter (4 $\mathrm{mm})$.

\section{Clinical signs and gross changes}

Clinical findings observed on the 60 diseased catfish during the sampling for this study were different among the fish. Some of diseased catfish display one clinical sings while others showed more than two clinical sings. These clinical findings included: dermal lesions with focal hemorrhage, ulcers, inflammation and hyperaemia of the fin bases. A "washboard" appearance on skin due to the scales bristling out, exophthalmia in one or both eyes, and eventual bursting of the orbit, an accumulation of fluid in the scale pockets; abdominal distention as a result of an edema; dark green pustules on the liver with yellowish foci on the surface; gall bladder contained emerald green bile; swollen and friable kidney and spleen (Figures 4 and 5).

\section{Discussion}

A. hydrophila is one of the major sources of disease complications for farmed fishes [20,21]. Ye concluded that A. hydrophila is a foodborne pathogen causing zoonotic diseases spreading from animals to humans based on twenty $A$. hydrophila isolates from sixty diseased freshwater fish that were characterized by antibiotics susceptibility testing, RAPD-PCR fingerprinting and detection of their virulence factors [22]. Another study by Daskalov [23] also showed A. hydrophila as being widely distributed in food, drinking water and environment, and as an important pathogen causing freshwater fish hemorrhagic diseases, zoonotic diseases, and food borne infections. Multiple factors can be involved in the virulence processes of Aeromonas hydrophila. In this study, eleven isolates of Aeromonas hydrophila were derived from diseased fresh water fishes of different species. Aeromonas hydrophila is naturally found in the intestinal tract of the fish, and does not produce

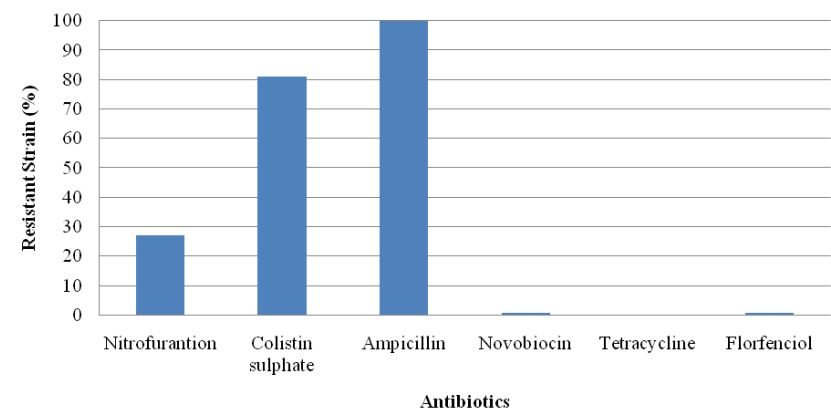

Figure 2: Percentage of bacteria strains resistance to antibiotics. 
Citation: Laith AR, Najiah M (2013) Aeromonas hydrophila: Antimicrobial Susceptibility and Histopathology of Isolates from Diseased Catfish, Clarias gariepinus (Burchell). J Aquac Res Development 5: 215 doi:10.4172/2155-9546.1000215

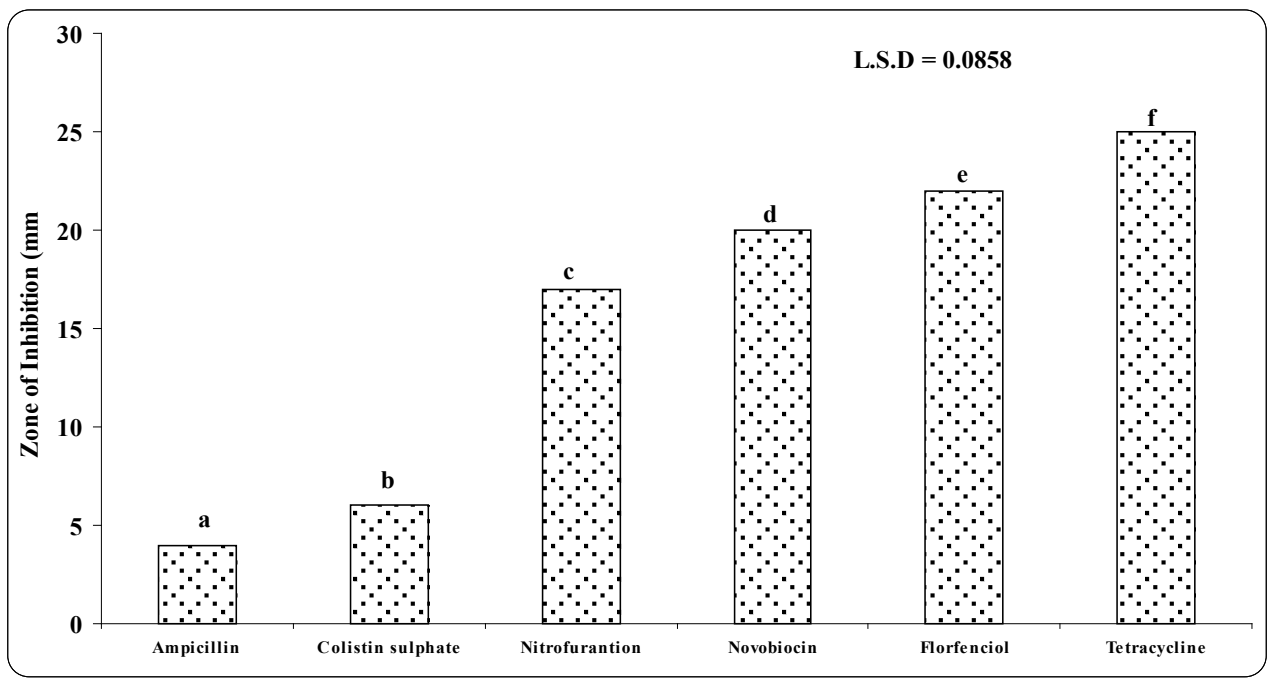

Figure 3: Showing the Diameter of Inhibition zones of antibiotics against Aeromonas hydrophila). Column with the different alphabets consider a significant different $(\mathrm{P}<0.05)$.
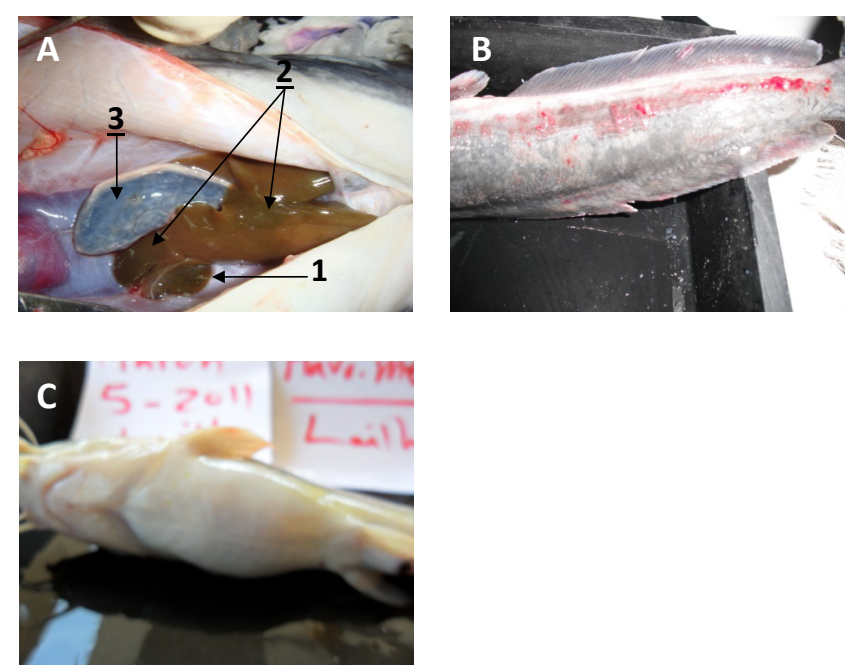

Figure 4: A. Yellow foci on the parietal surface of the liver [1] Greencolor of liver [2] and enlarged gall bladder filled with emerald-green secretion [3] B. Hemorrhage of the skin. C. Ascites.

disease under natural conditions. Disease outbreaks are usually brought on by factors including: stress, changes in environmental conditions, overcrowding, handling, transportation, poor water quality, changes in temperature, low dissolved oxygen, high $\mathrm{CO}_{2}$ levels, high nitrite levels, and high ammonia levels. These are the most common predisposing factors associated with A. hydrophila diseases. Moreover, the pathogenicity of Aeromonas hydrophila appears to be associated to stress of the host, Aeromonas hydrophila with high virulence can infect healthy fish; however, the stress coming from intensive fish farming also contributes and triggers outbreaks [24].

The spreading of drug resistance amid Aeromona spp. is also of risk since surveys indicated the emergence of these organisms as primary human pathogens [5]. Six antibiotics namely; ampicillin, tetracycline, nitrofurantoin, colistin sulphate, florfenicol, and novobiocin were used in the study mainly due to their routine usage in the prevention and treatment of fish disease in most fish farming in this area. Tetracycline and oxytetracycline are commonly applied for the treatment of $A$.
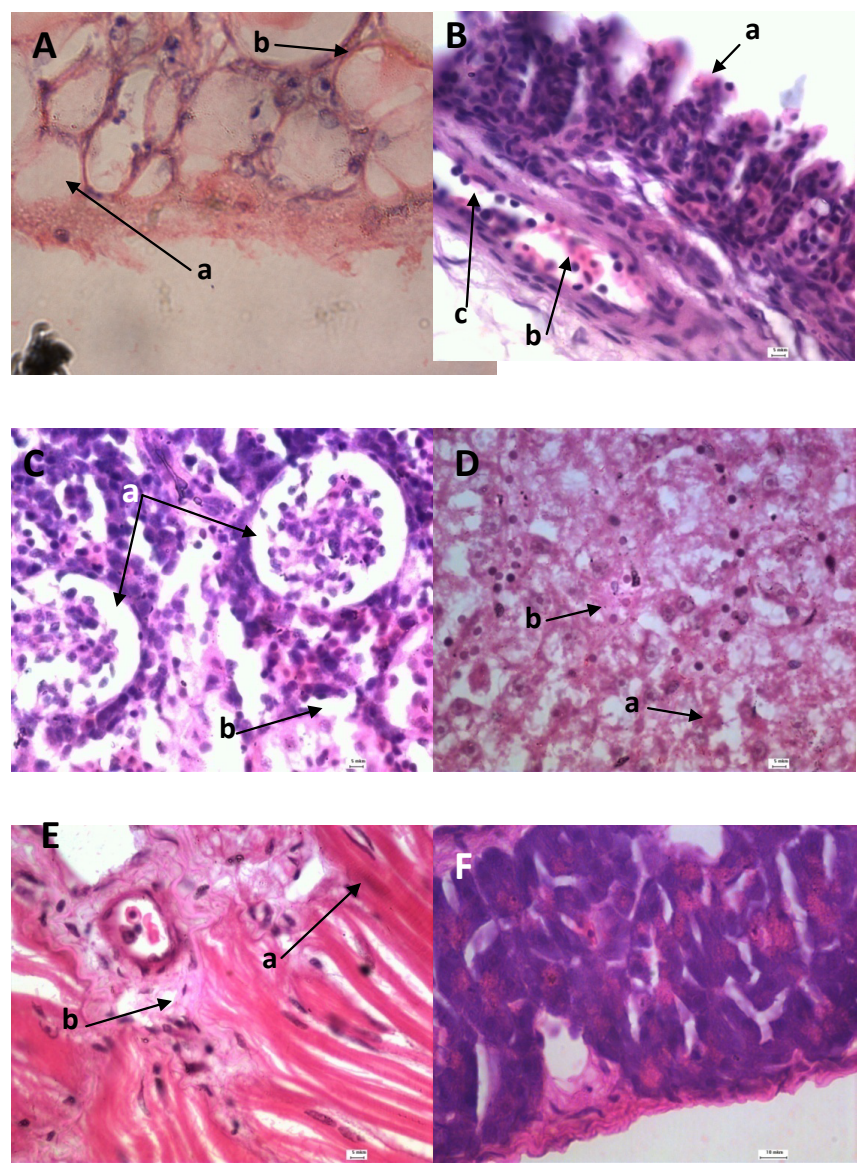

Figure 5: Histopathological section of A: Skin; (a) necrosis in the dermal layer (b) hypertrophy in immersion group with (H\&E stain100X). B: Gill; (a) hyperplasia in the secondary lamellae (b) leukocytic infiltration(c)dilation of the central venous sinus (H\&E stain100X) C: Kidney; (a) degenerative changes in glomerular epithelium (b) inflammatory cells (H\&E stain 100X) D: liver; (a) hepatocytes vacuolar degeneration (b) inflammatory cells (H\&E stain 100X) E: Muscles; (a) mild edema (b) focal hyaline degenerationF: Spleen; hyperplasia in the lymph follicles. 
hydrophila infections. The aeromonads have been regarded as being universally resistant to penicillins [5]; therefore, ampicillin has been incorporated in the culture media for selective isolation of the aeromonads from contaminated samples. The goal in this study was to confirm that $A$. hydrophila is resistant to penicillin but sensitive to tetracycline. Our results indicate that $A$. hydrophila showed resistance to more than two antibiotics, especially to ampicillin and colistin sulphate.

Results of the present study revealed that $73.3 \%$ of bacterial strains isolated from diseased catfish, Clarias gariepinus (Burchell) were A. hydrophila, and $6.6 \%$ were Pseudomonas aeruginosa, Klebsiella pneumoniae, Flavobacterium indicum, Chryseobacterium indologenes and Chryseobacterium gleum. Therefore, due to these findings we focused on Aeromonas hydrophila for their dominance. The causation of bacterial disease in ornamental fish studied in Malaysia aquarium shop [7] stated that the majority of bacterial disease in ornamental fish was (60\%) A. hydrophila, these results were similar with our findings that $A$. hydrophila is the most common (73.3\%) bacterial disease pathogen in farmed catfish. The present study also reveals that all bacterial strains had $(100 \%)$ of antibiotic resistance against ampicillin antibiotics the results were relatively similar to the study of [25] who determined antimicrobial susceptibility testing of $A$. hydrophila isolated from water and stool samples using disk diffusion method, that $100 \%$ of isolates were resistant to ampicillin. However, our finding is compatible with previous report of Jongjareanjai [26-29].

The disc diffusion method describe by Bauer [20] is a widely accepted in vitro investigation for preliminary screening of test agents which may possess antimicrobial activity. The antibiotics susceptibility test was achieved by [27] using disc diffusion method against $A$. hydrophila isolated from fish and the result showed eight isolates were resistant to ampicillin and colistin sulphate antibiotics. The report on drug resistance of motile Aeromonas spp. of fresh water fish farm by Hatha [28] showed that $100 \%$ of bacteria tested were resistant to ampicillin. These findings were in contrast with studies from Maurel [29] that A. hydrophila isolated from bullfrog were resistant to ampicillin. The continuous use of antibiotics with a high dosage in the farming areas is highly associated with the occurrence of resistant microorganism, probably by the transferring resistant plasmids or intergons [30].

(MAR) index exposes the spread of bacteria resistance in a given population. MAR index greater than 0.2 indicates that the bacterial strain derives from an environment where numerous antibiotics are used [31].

Multiple drug resistance was as well present in A. hydrophila isolates. It has been suggested that aquatic environments serve as important reservoirs of Aeromonas spp. that are able to cause human infections and these bacteria are capable of multiplying and growing in a variety of limnetic environments [32].

In this study the multi-drug resistant of the A. hydrophila were resistant to ampicillin and colistin sulphate antibiotics were relatively similar to other studies that have been reported $[27,32]$.

MAR index in the present study ranged from 0.1 to 0.5 and this finding are in accordance to the previous study of Jacobs and Chenia [33] stated that when the MAR index is in the range of 0.20-0.30 it indicate the source of origin which could be from commercial industry.
According to the results obtained in this study, control measures should be designed to deal with opportunist infections. Therefore, an antimicrobial susceptibility test against bacterial disease fish has to be completed in cage cultured fish.

Multiple factors are involved in the virulence processes of Aeromonas hydrophila. In this study, the virulence factors were widely distributed among the A. hydrophila isolates. Aerolysin was the most frequent virulence factor found in the analyzed isolates [34]. The lipases and hiydrolipases are important virulence factors in Aeromonas spp, they alter the structure of the cytoplasmic membrane of the host thus exacerbating its pathogenicity, especially if the aerolysin gene is present [35]. Moreover, the hemolytic activity of $A$. hydrophila as $\beta$-hemolysis may be used as an indicator of enterotoxicity [36] and this result are in agreement with our finding that all isolates of $A$. hydrophila were $\beta$-hemolysis, and are relatively similar to Khalil and Mansour [37], who described A. hydrophila as having a wide range of biological functions related to $\beta$-haemolysin (aerolysin) containing haemolytic and proteolytic activities lethal to fish. Despite the fact that inpotentially pathogenic aeromonads very few studies have included A. hydrophila strains. For example such isolate from European Seabass (Dicentrarchus labrax) fish could be enterotoxigenic and may be responsible for outbreaks of diarrhea if the fish are consumed without proper cooking; and media containing ampicillin may not be suitable for isolation of $A$. hydrophila [38]. Haemorrhage at the anusand blood-stained ascites has been detected in several fish infected with $A$. hydrophila. Clinical signs and gross changes were similar to those described in naturally infected rainbow trout [39].

Skin lesions with focal hemorrhage and inflammation may be related to Aeromonas spp. infections associated with ulcerative skin and may be on the surface of organ or deep within tissue [40]. Our findings were also similar with the findings of Cipriano [8] who stated that the chronic infections of $A$. hydrophila led to dermal ulceration lesions with focal haemorrhages and inflammation. The present study revealed hemorrhages of the pectoral fin had been seen in the diseased fish, these results were relatively similar to the study of Suprapto [41] that the hemorrhage of the pectoral fin is prominent. Our histopathological results are in agreement with Harikrishnan and Balasundaram [42] stated that $A$. hydrophila causes hemorrhagic sepsis, characterized by small superficial wounds and localized bleeding which evolve to epidermal wounds. Exophthalmia seen in some cases in the present study are similar to those reported inYambot and Inglis [43] who described an acute mortality among Nile tilapia (Oreochromis niloticus) infected with $A$. hydrophila and the most apparent clinical signs included an opaqueness in one or both eyes, accompanied by exophthalmia and eventual bursting of the orbit. Arrangements of hepatocytes in the liver were disturbed showing some cells with vacuolation with sever necrosis. The present study exhibited results relatively similar to Afifi [44] that toxins produced by $A$. hydrophila and extracellular products such as hemolysin, protease, elastase may cause severe necrosis in the liver.

Our study also observed that the kidneys of the diseased fishes were severely damaged, exhibiting degenerative changes in the glomerular epithelium with cytoplasmic vacuol formation, as well as focal lymphocyte infiltration similar to the report of Suprapto [41] stating that kidney attacked by bacterial toxins led to kidney cells to lose their structural integrity.

\section{Conclusion}

These results show that the strains in sample developed antibiotic 
Citation: Laith AR, Najiah M (2013) Aeromonas hydrophila: Antimicrobial Susceptibility and Histopathology of Isolates from Diseased Catfish, Clarias gariepinus (Burchell). J Aquac Res Development 5: 215 doi:10.4172/2155-9546.1000215

resistance. Therefore, a further development of the resistance may be expected, consequently the number of effective antimicrobial drugs is diminishing. Since this is a microorganism that may threaten human health, transmission of the reduced susceptibility may have negative consequences for humans.

\section{Acknowledgements}

The authors would like to thank the ministry of Agriculture (MOA) Malaysia 05-10-12-SF1009 for providing the research funding.

\section{References}

1. Shak JR, Whitaker JA, Ribner BS, Burd EM (2011) Aminoglycoside-Resistan Aeromonas hydrophila as Part of a Polymicrobial Infection Following a Traumatic Fall into Fresh Water. J Clin Microbiol 49: 1169-1170.

2. Saavedra MJ, Guedes-Novais S, Alves A, Rema P, Tacao M, et al. (2004) Resistance To B-Lactam Antibiotics in Aeromonas hydrophila Isolated From Rainbow Trout (Oncorhynchus mykiss). Int Microbiol 7: 201-211.

3. Chugh, TD (2008) Emerging and Re-Emerging Bacterial Diseases in India. $J$ Biosci 33: 549-555.

4. Yu HB, Rao PSS, Lee HC, Vilches S, Merino S et al. (2004) A Type III Secretion System is Required for Aeromonas hydrophila $\mathrm{AH}-1$ Pathogenesis. Infect Immun 72: 1248-1256.

5. Rey G, Fouillet A, Bessemoulin P, Frayssinet P, Dufour A, et al (2009) Heat Exposure and Socio-Economic Vulnerability as Synergistic Factors in HeatWave-Related Mortality. European Journal of Epidemiology 24: 495- 502.

6. Roberts RJ, Macintosh DJ, Tonguthai K, Boonyaratplain S, Tayaputch N et al (1986) Field and Laboratory Investigations into Ulcerative Fish Diseases in the Asia-Pacific Region. Bangkok: FAO.

7. Musa N, Wei LS, Shaharom F, Wee W (2008) Surveillance of Bacteria Species in Diseased Freshwater Ornamental Fish From Aquarium Shop. World Applied Sciences Journal 3: 903-905.

8. Cipriano RC, Bullock GL, Pyle SW (2001) Aeromonas hydrophila and Motile Aeromonad Septicemias of Fish. Fish Disease Leaflet 68, US Department of the Interior Fish \& Wildlife Service, Washington.

9. Austin B, Austin DA (2007) Bacterial Fish Pathogens, Disease of Farmed and Wild Fish, 4th Ed. Springer Praxis, Godalming.

10. Huizinga HW, Esch GW, Hazen TC (1979) Histopathology of Red-Sore Disease (Aeromonas hydrophila) in Naturally and Experimentally Infected Largemouth Bass Micropterus salmoides (Lacepede). J Fish Dis 2: 263-277 International Journal of Microbiology 92: 275-287.

11. Wooley RE, Ritchie BW, Burnley VV (2004) In Vitro Effect of a Buffered Chelating Agent and Neomycin or Oxytetracycline on Bacteria Associated with Diseases of Fish. Dis Aquat Org 59: 263-267.

12. Wilson JM, Bunte RM, Carty AJ (2009) Evaluation of Rapid Cooling and Tricaine Methanesulfonate (MS222) as Methods of Euthanasia in Zebrafish (Daniorerio). Journal of The American Association For Laboratory Animal Science 48: 785-789.

13. Buller NB (2004) Bacteria From Fish and Other Aquatic Animals: A Practica Identification Manual. CABI Pub.

14. Yogananth NR, Bhakyaraj A, Chanthuru T, Anbalagan, Mullainila K (2009) Detection of Virulence Gene in Aeromonas hydrophila Isolated From Fish Samples Using PCR Technique. Global Journal of Biotechnology \& Biochemistry 4: 51-53.

15. Flemming L, Rawlings D, Chenia H, (2007) Phenotypic and Molecular Characterisation of Fish-Borne Flavobacterium johnsoniae-Like Isolates From Aquaculture Systems in South Africa. Res Microbiol 158: 18-30.

16. Clinical and Laboratory Standard Institute (CLSI) (2006) Performance Standard for Antimicrobial Susceptibility Testing; Sixteenth Information Supplement, M-100-S 16. CLSI: Wayne (PA).

17. Trust TJ, Sparrow RAH (1974) The Bacterial Flora in The Alimentary Tract of Freshwater Salmonid Fishes. Canadian Journal of Microbiology 20: 1219-1228.

18. Pavlov D, DeWet CM, Grabow WO, Ehlers MM (2004) Potentially Pathogenic Features of Heterotrophic Plate Count Bacteria Isolated From Treated and Untreated Drinking Water. Int J Food Microbiol 92: 275-287.
19. Carleton HM, Drury RAB, Wallington EA (1967) Carleton's Histological Technique. Fourth Edition.

20. Bauer AW, Kirby WMN, Sherris JC, Turck M (1966) Antibiotic Susceptibility Testing by a Standardized Single Disc Method. Am J Clin Pathol 45: 493-496.

21. Guz L, Kozinska A (2004) Antibiotic Susceptibility of Aeromonas hydrophila and A. sobria Isolated From Farmed Carp (Cyprinus carpio L). Bull Vet Inst Pulawy 48: 391-395.

22. Ye YW, Fan TF, Li H, Lu JF, Jiang H, et al. (2013) Characterization of Aeromonas hydrophila From Hemorrhagic Diseased Freshwater Fishes in Anhui Province, China. International Food Research Journal 20: 1449-1452.

23. Daskalov H (2006) The Importance of Aeromonas hydrophila in Food Safety. Food Control 17: 474-483.

24. Suomalainen LR, Tiirola M, Valtonen ET (2005) Influence of Rearing Conditions on Flavobacterium columnare Infection of Rainbow Trout, Oncorhynchus mykiss (Walbaum). J Fish Dis 28:271-277.

25. Ramalivhana JN, Obi CL, Moyo SR (2009) Antimicrobial Susceptibility Testing of Aeromonas hydrophila Isolated From Limpopo Province, South Africa Using VITEK 2 System, Micro Scan Walk Away, Disk Diffusion and E-Test Method. African Journal of Microbiology Research 3: 903-913.

26. Jonjareanjai M, Assawawongkasem N, Chansue N (2009) In Vitro Antibiotic Susceptibility of Aeromonas hydrophila Isolated From Disease Ornamenta Fish. Thai J Vet 39: 225-229.

27. Kaskhedikar M, Chhabra, D (2010). Multiple Drug Resistance in Aeromonas hydrophila Isolates of Fish. Vet World 32: 76-77.

28. Hatha M, Vivekanandhan AA, Joice GJ, Christol (2005) Antibiotic Resistance Pattern of Motile Aeromonads from Farm Raised Fresh Water Fish. Int J Food Microbial 98: 131-134.

29. Maurel C, Javot H, Lauvergeat V, Gerbeau P, Tournair C, Santoni V, Heyes, $\mathrm{J}$ (2002) Molecular Physiology of Aqua Porins in Plants. Int Rev Cytol 215 $105-148$.

30. Kummerer K (2009) Antibiotics in the Aquatic Environment -A Review- Part II. Chemosphere 75: 435-441.

31. Ehinmidu JO (2003) Antibiotics Susceptibility Patterns of Urine Bacterial Isolates in Zaria, Nigeria. Trop J Pharm Res 2: 223-28.

32. Hoi L, Larsen JL, Dalsgaard I, Dalsgaard A (1998) Occurrence of Vibrio vulnificus Biotypes in Danish Marine Environments. Applied and Environmenta Microbiology 64: 7-13.

33. Jacobs L, Chenia HY (2006) Characterization of Integrons and Tetracycline Resistance Determinants in Aeromonas spp. Isolated From South African Aquaculture Systems. Int J Food Microbiol 13: 1717-3998.

34. Samira TLO, Gisele VG Mateus MC (2012). Molecular Characterization of Virulence Factors in Aeromonas hydrophila Obtained From Fish. Pesq Vet Bras 32: 701-706.

35. Nawaz M, Khan SA, Khan AA, Sung K, Tran Q, et al. (2010) Detection and Characterization of Virulence and Integrons in Aeromonas veronii Isolated From Catfish. Food Microbiol 27: 327-331.

36. Rahim Z, Sanyal SC, Aziz KMS, Huq MI, Chowdhury AA (1984) Isolation of Enterotoxigenic, Hemolytic and Antibiotic-Resistant Aeromonas hydrophila Strains From Infected Fish In Bangladesh. Appl Environ Microbiol 48: 865-867.

37. Khalil AH, Mansour EH (1997) Toxicity of Crude Extracellular Products of Aeromonas hydrophila in Tilapia, Tilapia nilótica. Letters in Applied Microbiology 25: 269-272.

38. Namdari H, Bottone EJ (1990) Microbiologic and Clinical Evidence Supporting the Role of Aeromona scaviaeas, A Pediatric Enteric Pathogen. J Clin Microbio 28: $837-840$.

39. Aydın S, Celebi S, Akyurt I (1997) Clinical, Heamatological and Pathological Investigation of Esherichia vulneris In Rainbow Trout (Oncorhynchus mykiss) Fish Pathology 32: 29-34.

40. Hirono I, Aoki T (1991) Nucleotide Sequence and Expression of an Extracellular Haemolysin Gene of Aeromonas hydrophila. Microb Pathog 11: 189-197. 
Citation: Laith AR, Najiah M (2013) Aeromonas hydrophila: Antimicrobial Susceptibility and Histopathology of Isolates from Diseased Catfish, Clarias gariepinus (Burchell). J Aquac Res Development 5: 215 doi:10.4172/2155-9546.1000215

41. Suprapto H, Sumartiwi L, Prawesthirini S, Handiyatno D, Azmijah A (2005) The Isolation of Aeromonas hydrophila and Escherichia coli From Lou Ham Cichlasoma synspilum and Studies of Their Histopathology Changes. Berk Penel Hnyafi 10: 139-141.

42. Harikrishnan R, Balasundaram C (2005) Modern Trends in Aeromonas hydrophila Disease Management With Fish. Rev Fish Sci 13: 281-320.
43. Yambot AV, Inglis V (1994) Aeromonas hydrophila Isolated From Nile Tilapia (Oreochromis niloticus) With "Eye Disease". In: International Symposium on Aquatic Animal Health, University of California, School of Veterinary Medicine Davis, CA. 103.

44. Afifi SH, Al-Thobiati S, Hazaa MS (2000) Bacteriological and Histopathological Studies on Aeromonas hydrophila Infection of Nile Tilapia (Oreochromis niloticus) From Fish Farms in Saudi Arabia. Assiut Vet Med J 84: 195205 